\title{
Barnita Bagchi, Eckhardt Fuchs, and Kate Rousmaniere, eds. Connecting Histories of Education: Transnational and Cross-Cultural Exchanges in (Post)Colonial Education
}

\author{
NewYork: Berghahn, 2014. 255 pp.
}

\section{Robyn Sneath \\ University of Oxford}

Rarely does a book come along that simultaneously fills lacunae in multiple areas of education research. Connecting Histories of Education does precisely that; ambitious in scope, the volume is a collection of thirteen case studies that relate broadly to issues of transnationalism, postcolonialism, and history of education, with the collective goal of complicating conventional assumptions of hegemonic pedagogical agendas attendant with colonial projects. To be sure, education served as a primary tool of "indoctrination and acculturation" (142); however, as each of the cases demonstrates, the influence was not nearly as unidirectional as has been hitherto apprehended.

Editors Barnita Bagchi, Eckhardt Fuchs, and Kate Rousmaniere state in the introduction that the purpose of this volume is to connect non-European scholarship "with the goal of highlighting the interconnectedness of histories of education in the modern world" (1). The endeavour is transnational in several respects - both contributors and the foci of their contributions is impressively global (though worth noting is the predominant focus on Southeast Asia), and tying each of the disparate sections together is a common emphasis on the multi-directionality of transcultural transmission. Both formal and informal education are examined and the volume addresses four major themes: historiographical reflections; travelling concepts; Indigenous education and resistance; and women's education.

In part one, Historiographical Reflections, contributors consider the relationship between transnationalism and the history of education. Rather than the centre-influencing-the-periphery trope common to earlier postcolonial scholarship, this book 
emphasizes a tangled web of reciprocity. In the opening chapter, Fuchs argues that the history of education has been slow to move beyond the constraints of the nation state, but that the paradigm shift initiated by globalization requires a new conceptualization of the notion of space, "not a matter of deconstructing national history but of contextualizing it" (15). Sabyasachi Bhattacharya, in the second chapter, notes that global histories of education have typically assumed either a diffusionist or an aggregate approach where, in the case of the former, the focus is on the dissemination of practices or paradigms, or, in the case of the latter, a collection of disparate national histories of education is lumped together and referred to as "global" (27). In contrast, what he proffers is the study of histories of education through a civilizational approach, which inherently involves a conversation beyond national borders and which is the perspective adopted, either implicitly or explicitly, by the other contributors.

Several pieces note that transcultural interactions led to outcomes unintended by colonizers and their agents. In the section, Travelling Concepts, Mary Hilton presents the work of an early nineteenth-century Baptist missionary to Bengal, William Carey, and effectively demonstrates that a particular type of literacy instruction-which involved the parsing of texts into words and lists, the goal of which was to lead to the ability to read the Bible - had the very unintended consequence of inspiring a flourishing of literary works in the Bengali vernacular. Jana Tschurenev argues that the monitorial system, which came to dominate Great Britain in the early nineteenth century, actually originated in Madras, India, and was based on a combination of Hindu pedagogy and Scottish Enlightenment thought.

In the section on Indigenous education and resistance, the authors illustrate how education served as the primary tool of the oppressor, but they also note that education served also as a tool to resist oppression. Daniel Lindmark, in his chapter on Swedish residential schooling for Saami children in Sápmi in the seventeenth century, presents the case studies of two adolescent Saami boys, both of whom initially resist the schooling agenda of their colonizer. The first boy eventually acquiesces to proselytizing pressure, while the latter uses the tools he gained to advocate for traditional Saami rights through a series of letters written to Swedish authorities.

The final section, Women's Education, is the least contiguous, and ostensibly has the most tenuous connection to the theme of the volume. While there is an obvious triangulation among the first three sections, three of the four chapters in this final section mark a noticeable departure in content and evidence. The focus here is largely on informal rather than formal education, and is analyzed through women's writing. The last chapter in the section serves as a de facto conclusion for the volume, and in it, through a history of Loreto, a Catholic women's teaching order in India, Tim Allender reminds the reader of the importance of "theorization about knowledge transfer that goes beyond simpler centre-periphery binaries" (227).

Connecting Histories of Education provides nuance to what for too long has been regarded as a one-way relationship, where the colonizers spread their tentacles of influence through the colonized world. While this is likely not the first time this argument has been made, what is novel here is its application to histories of education, and the use of a transnational lens to reflect and refract aspects of this relationship, 
revealing a multifaceted web of mutual influence. If anything, the work feels like a first step, an overdue contribution to the subfields of education research noted above. Each of the four sections could easily comprise a work unto itself and, indeed, next steps may warrant further exploration in the respective areas. The section on transcultural Indigenous responses is particularly apposite, as several countries, including Canada, contemplate their own dark history of residential schools for Indigenous children. Though each of the case studies considers transcultural knowledge transfers in disparate cultural contexts - Java, Mexico, Belgian Congo, India - to name a few, the unifying thread is a consensus that " 'colonial ground' was no tabula rasa waiting to be inscribed with the knowledge of the colonizers" (116). 